\title{
Amorphization of a crystalline active pharmaceutical ingredient and thermoanalytical measurements on this glassy form
}

\author{
Orsolya Jójárt-Laczkovich • Piroska Szabó-Révész
}

Received: 30 June 2009/ Accepted: 29 September 2009/Published online: 5 November 2009

(C) The Author(s) 2009. This article is published with open access at Springerlink.com

\begin{abstract}
Amorphization is nowadays a method that is frequently applied in the pharmaceutical industry. The primary aim of this study is to achieve the amorphization of clopidogrel hydrogen sulphate as an active pharmaceutical ingredient (API) with various solvents and to choose the most suitable one. A secondary aim was to determine the glass-transition temperature $\left(T_{\mathrm{g}}\right)$ of this API and to classify it as a good or poor glass former. To investigate the amorphous form, differential scanning calorimetry, X-ray powder diffraction, and FT-IR analysis were applied. The melting point $\left(T_{\mathrm{m}}\right)$ was $177.4{ }^{\circ} \mathrm{C}(450.6 \mathrm{~K})$, and $T_{\mathrm{g}}$ was determined to be $88.9{ }^{\circ} \mathrm{C}(362.1 \mathrm{~K})$. The quotient $T_{\mathrm{g}} / T_{\mathrm{m}}$ was 0.80 , and this API was therefore classified as a good glass former.
\end{abstract}

Keywords Amorphization - Clopidogrel hydrogen sulfate - DSC · FT-IR spectroscopy · Solvent method · $T_{\mathrm{g}} \cdot \mathrm{X}$-ray powder diffraction

\section{Introduction}

The two forms of solids are the amorphous and the crystalline forms [1]. The amorphous form is widely applied in industrial fields such as the plastics industry, the textile industry, the food industry, the production of semiconductors, ceramics and optical glasses, and naturally the pharmaceutical industry. The importance of amorphization

O. Jójárt-Laczkovich · P. Szabó-Révész $(\bowtie)$

Department of Pharmaceutical Technology, University

of Szeged, Eötvös u. 6, 6720 Szeged, Hungary

e-mail: revesz@pharm.u-szeged.hu is currently increasing in consequence of its value in the pharmaceutical industry for various reasons [2]:

- The development of many poorly water-soluble active pharmaceutical ingredients (APIs) [3].

- The polymorphism of APIs, the different forms having different physical and/or chemical properties [4], which can be interconverted and thus display changing solubility, compressibility, and not at least physiological effects.

- The processing of crystalline drug substances lead run into difficulties, whereas the amorphous form can often be treated easily. In many cases, for example, the compressibility of the amorphous form is better than that of the crystalline form [1].

- Economic aspects are also involved when the aim of amorphization is a new patent relating to the amorphous form.

Amorphous forms of APIs have many useful properties. Some of the most important ones: higher water solubility and higher dissolution rate relative to the crystalline forms [5-8], as there is no lattice energy, which is a thermodynamic barrier to dissolution [9]. There are two feasible ways to amorphize crystalline APIs:

- An amorphous API can be produced alone, without additives, but it must be mentioned that amorphous solids generally have lower stability than the corresponding crystals because of the higher energy level [10-12].

- Otherwise, pharmaceutical technologists often have to apply crystallization inhibitors as additives [13-15]. These inhibitors are usually hydrophilic carriers, which can increase the wetting property of APIs too. This mostly results in more stable product. 
Both routes for the amorphization of crystalline APIs can be applied with the solvent method, hot-melt technology and milling technology [16].

The solvent method is one of the simplest processes for amorphization in industry. It is important that the agent must dissolve without leaving a residue. If crystals remain in the system, then these could start nucleation by acting as seeding crystals in the phase of supersaturation during the evaporation of the solvent.

In pharmaceutical systems, amorphous materials are of great importance both as auxiliary agents and as APIs.

Crystalline systems can be characterized by their melting points $\left(T_{\mathrm{m}}\right)$, but amorphous materials do not possess this characteristic temperature parameter. They can rather be defined by the glass-transition temperature $\left(T_{\mathrm{g}}\right)$, below which amorphous materials are brittle and above which they are in a liquid or rubbery state. The $T_{\mathrm{g}}$ lies in the interval from approximately $2 / 3$ to $4 / 5$ of the $T_{\mathrm{m}}$ (in Kelvin) [2]. For investigations of the amorphous form and $T_{\mathrm{g}}$, the differential scanning calorimetry (DSC) is a suitable experimental method [17, 18].

Crystalline agents can be divided into poor (or fragile) glass formers and good (or strong) glass formers. In the case of poor or fragile glass formers $T_{\mathrm{g}} / T_{\mathrm{m}}<0.7$, and in the case of good or strong glass formers $T_{\mathrm{g}} / T_{\mathrm{m}}>0.7$ [19]. (In an another publications the limit is given as 1.5 , but in this case the quotient is $T_{\mathrm{m}} / T_{\mathrm{g}}$, when $T_{\mathrm{m}} / T_{\mathrm{g}}>1.5$ the material is good glass former $[11,20]$.) Good glass formers exhibit minimal molecular mobility changes at $T_{\mathrm{g}}$, and hence the shift in heat capacity tends to be small.

In this study, the crystalline API which was subjected to amorphization was clopidogrel hydrogen sulfate (clopidogrel bisulfate) (CLP), a potent oral antiplatelet agent often used in the treatment of coronary artery disease, peripheral vascular disease, and cerebrovascular disease as Plavix ${ }^{\circledR}$ or Iscover $^{\circledR}$ [21]. The chemical formula is $\mathrm{C}_{16} \mathrm{H}_{16} \mathrm{ClNO}_{2} \mathrm{~S}$ $\mathrm{H}_{2} \mathrm{SO}_{4}$ and the molecular mass is 419.9. Chemically it is classed among the thiophenes, and its systematic IUPAC name is methyl (+)-(S)-alpha-(2-chlorophenyl)-6,7-dihydrothieno[3,2-c]pyridine-5(4H)-acetate sulfate. Six different polymorphic forms and an amorphous form of the drug have been identified, but only forms I and II are used in pharmaceutical formulations [22, 23]. The polymorphic and amorphous forms of this drug are dealt within a number of patents and articles [24-26].

The primary aim of this study is to achieve the amorphization of CLP by the solvent method and to select the most suitable solvent. A further aim is to characterize the amorphous form via thermoanalytical parameters and to classify it as a poor or a good glass former. We additionally carried out preliminary stability testing of the pure amorphous CLP.

\section{Materials and methods}

Materials

CLP polymorphic form II (EGIS, Budapest, Hungary) was used as the crystalline API. Ethanol (Merck, Budapest, Hungary), methanol (Merck, Budapest, Hungary), and acetone (Reanal, Budapest, Hungary) were used as solvents.

Methods

Preparation of amorphous form

Amorphous samples were made using ethanol and methanol. 1.00-g CLP was dissolved in 10.00-g ethanol or 4.00-g methanol with magnetic stirrer (Velp ${ }^{\circledR}$ Scientifica, Europe) for $5 \mathrm{~min}$ at room temperature. The solvent was evaporated by two methods: with blown room temperature air or by vacuum (Binder, Germany). 1.00-g CLP was treated with 20.00-g acetone with magnetic mixing for $15 \mathrm{~min}$ at room temperature and the solvent was then evaporated in vacuum (Binder, Germany). After drying, samples were pulverized in a porcelain mortar with a pestle.

\section{Differential scanning calorimetry}

DSC studies were performed with a DSC $821^{\mathrm{e}}$ instrument (Mettler-Toledo, Switzerland) with samples of approximately $4.8-5.2 \mathrm{mg}$ weighed into non-hermetically sealed aluminum pans. The samples were heated from 25 to $200{ }^{\circ} \mathrm{C}$ at heating rate of $5{ }^{\circ} \mathrm{C} \mathrm{min}{ }^{-1}$. The instrument was calibrated with the use of indium.

\section{FT-IR analysis}

The FT-IR apparatus was an Avatar 330 FT-IR spectrometer (Thermo Nicolet, USA). The sample, with a CLP content of $0.5 \mathrm{mg}$, was ground and mixed with $150 \mathrm{mg}$ of dry $\mathrm{KBr}$ in an agate mortar, and the mixture was then compressed into a disk at $98.1 \mathrm{kN}\left(\mathrm{cm}^{2}\right)^{-1}$. Each disk was scanned 64 times at a resolution of $2 \mathrm{~cm}^{-1}$ over the wavenumber region $4000-400 \mathrm{~cm}^{-1}$.

\section{$X$-ray powder diffraction (XRPD)}

XRPD was performed with an X-ray Diffractometer Miniflex II (Rigaku, Tokyo, Japan), where the tube anode was $\mathrm{Cu}$ with $\mathrm{K} \alpha=1.5405 \AA$. The pattern was collected at a tube voltage of $30 \mathrm{kV}$ and a tube current of $15 \mathrm{~mA}$ in step scan mode $\left(4^{\circ} \min ^{-1}\right)$. The instrument was calibrated with Si. 


\section{Results and discussion}

\section{Confirmation amorphous form}

Prepared samples were measured primarily by DSC. With this method, characterization of the amorphous form is possible quickly. The starting material and five prepared samples were tested at first by DSC. These curves are presented in Fig. 1. The crystalline CLP melted at $177.4{ }^{\circ} \mathrm{C}$ $(450.6 \mathrm{~K})$. The normalized heat capacity change was $83.9 \mathrm{Jg}^{-1}$. The sample which was treated with acetone remained in the crystalline phase. The melting point of this material was $177.8{ }^{\circ} \mathrm{C}(450.9 \mathrm{~K})$ and the normalized heat capacity change was $82.6 \mathrm{Jg}^{-1}$. The samples prepared in ethanol or methanol were transformed to the amorphous form both on drying through blowing with room temperature air and with vacuum. The characteristic melting point disappeared completely from the DSC curves which were straight lines without any enthalpy changes; no $T_{\mathrm{g}}$ could be detected.

Samples were also tested by XRPD measurement. Diffractograms are can be seen in Fig. 2; for clarity, the diffractograms are displaced along the $y$ axis. This investigation supported the DSC results throughout. Figure 2 shows that the products prepared with ethanol or methanol, independently of the drying procedure were converted to the amorphous form, because the peaks disappeared from the diffractograms, and the spectra became smooth. The sample treated with acetone remained in the crystalline phase, and the diffractogram of this preparation was the same as that of the crystalline starting material.

To confirm that no degradation occurred in the prepared samples FT-IR analysis was performed (Fig. 3). For

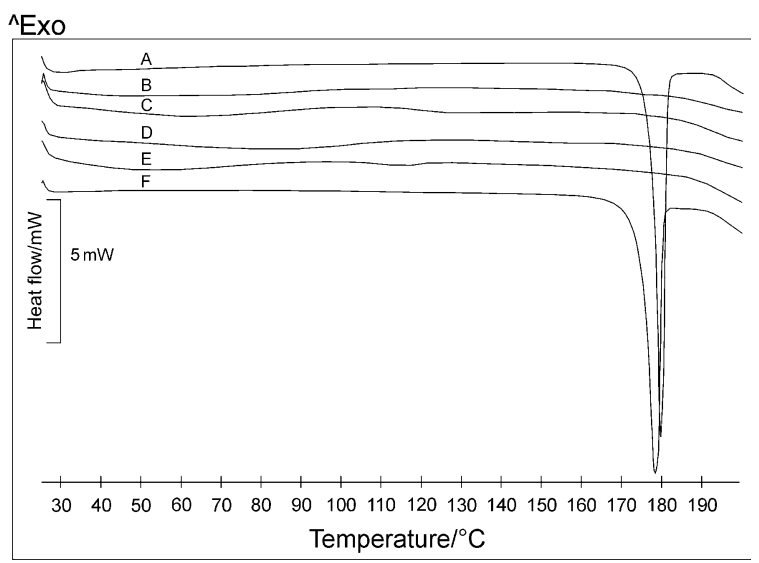

Fig. 1 CLP samples measured by DSC. (A) Crystalline form, (B) sample prepared with ethanol, dried with blowing of room temperature air, $(C)$ sample prepared with ethanol, dried by vacuum, (D) sample prepared with methanol, dried with blowing of room temperature air, $(E)$ sample prepared with methanol, dried by vacuum, $(F)$ sample treated with acetone, dried by vacuum

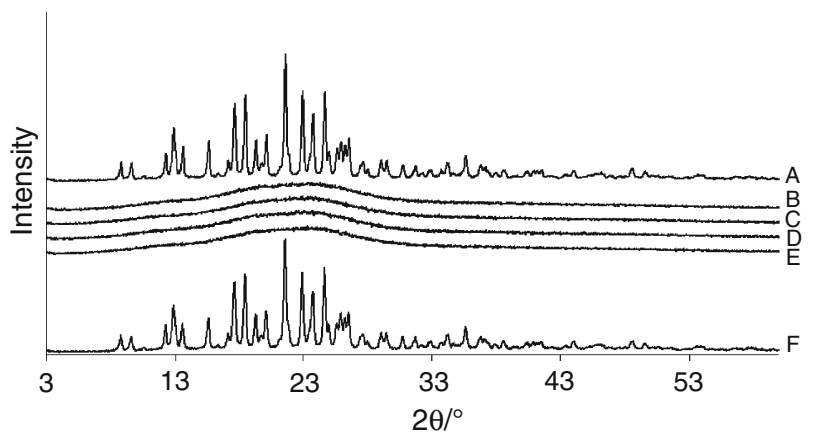

Fig. 2 CLP samples measured by XRPD. (A) Crystalline form, (B) sample prepared with ethanol, dried with room temperature air, (C) sample prepared with ethanol, dried by vacuum, (D) sample prepared with methanol, dried with room temperature air, $(E)$ sample prepared with methanol, dried by vacuum, $(F)$ sample treated with acetone, dried by vacuum

clarity, these spectra too have been displaced along $y$ axis. Each peak was present in each spectrum, reflecting the presence of the same chemical bonds and no degradation could be detected in the course of these measurements. The amorphous and crystalline materials furnished the same spectra. Thus, as we had anticipated with this method we could not differentiate the crystalline and the amorphous forms, but we confirmed that no degradation happened in samples.

The DSC, the XRPD, and the FT-IR results suggested that the samples prepared with ethanol or methanol were transformed to the amorphous form independently of the drying procedure, but the sample treated with acetone remained in the crystalline form. The acetone is not suitable solvent for amorphizing CLP, but ethanol and methanol have the same amorphizing property in the case

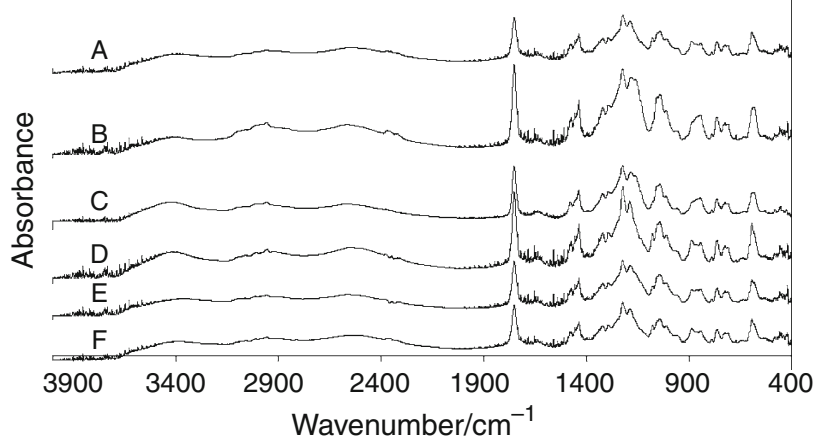

Fig. 3 CLP samples measured by FT-IR. (A) Crystalline form (P II), (B) sample prepared with ethanol, dried with room temperature air, (C) sample prepared with ethanol, dried by vacuum, (D) sample prepared with methanol, dried with room temperature air, $(E)$ sample prepared with methanol, dried by vacuum, $(F)$ sample treated with acetone, dried by vacuum 
of this API. If we apply a solvent in a pharmaceutical technological method, we must take care of the danger class of this solvent according to the ICH Q3C guideline [27]. The objective of this guideline is to recommend acceptable amounts for residual solvents in pharmaceuticals for the safety of the patient. ICH Q3C classifies ethanol into the less dangerous Class 3, while methanol is classified into the more dangerous Class 2. According to these facts, we suggest the application of ethanol for amorphizing CLP.

Measurement of $T_{\mathrm{g}}$

As mentioned in the Introduction, $T_{\mathrm{g}}$ is a very important parameter for amorphous materials. The expected temperature interval, in which $T_{\mathrm{g}}$ can lie, is approximately $2 / 3$ to $4 / 5$ of $T_{\mathrm{m}}$ (in Kelvin) [2]. The $T_{\mathrm{m}}$ of crystalline CLP is $177.4{ }^{\circ} \mathrm{C}(450.6 \mathrm{~K})$. Accordingly, the expected interval of glass transition is $27.2-87.3{ }^{\circ} \mathrm{C}$ (300.4$360.4 \mathrm{~K}$ ), in this temperature interval we expected the appearance of $T_{\mathrm{g}}$.

A DSC curve reveals all structural changes accompanied by enthalpy changes. In the curve, $T_{\mathrm{g}}$ is usually indicated by a step, a dislocation from the baseline. For CLP, however, during the first heating run $T_{\mathrm{g}}$ could not be detected, but during the second heating $T_{\mathrm{g}}$ appeared in the curve (Fig. 4). When double heating was carried out with two samples with ethanol, the endothermic step in the DSC curve was detected in the same interval. This temperature interval $82-110{ }^{\circ} \mathrm{C}(355-383 \mathrm{~K})$ can be defined as glass transition of CLP. The midpoints of these changes were $89.4{ }^{\circ} \mathrm{C}(362.6 \mathrm{~K})$ and $88.5^{\circ} \mathrm{C}(361.6 \mathrm{~K})$, with a mean of $88.9^{\circ} \mathrm{C}(362.1 \mathrm{~K})$. Thus for the calculation this mean of values $\left(88.9^{\circ} \mathrm{C}=362.1 \mathrm{~K}\right)$ was applied as $T_{\mathrm{g}}$. For CLP,

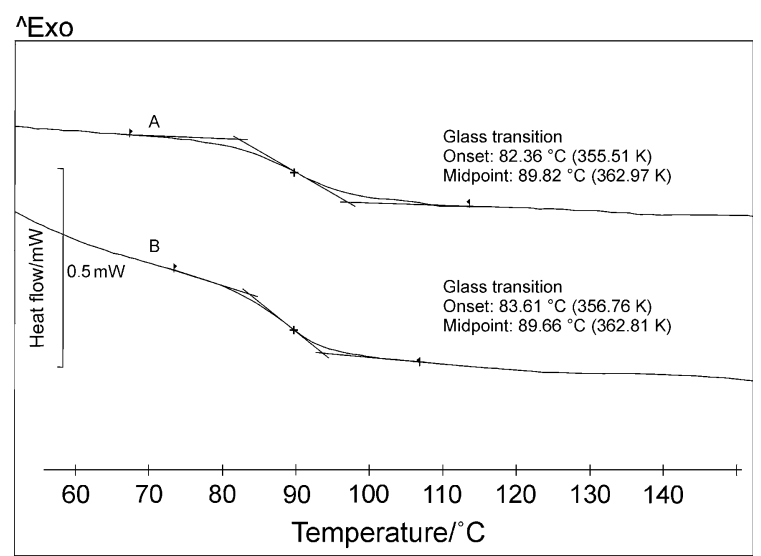

Fig. 4 Glass-transition temperature of CLP measured by DSC. (A) Sample prepared with ethanol, dried with room temperature air, (B) sample prepared with ethanol, dried by vacuum therefore the quotient $T_{\mathrm{g}} / T_{\mathrm{m}}$ is 0.80 , and accordingly this API can be classified as a good glass former.

Preliminary stability testing

In the case of amorphous materials, stability problems can occur because of the higher energy level. The possibility of recrystallization is very notable. The amorphous CLP was subjected to preliminary stability testing. A sample prepared with ethanol was stored in a closed glass container at $23 \pm 2{ }^{\circ} \mathrm{C}$ and $55 \pm 5$ relative humidity. It was observed that crystal growth started after 30 days (Fig. 5). The crystallinity of the sample increased for approximately 76 days and crystal growth then stopped. The characteristic $T_{\mathrm{m}}$ appeared in curve B at $172{ }^{\circ} \mathrm{C}(445.2 \mathrm{~K})$. This peak increased linearly with time, but the change stopped after 76 days. $T_{\mathrm{m}}$ was found in the interval of $170-172{ }^{\circ} \mathrm{C}$ (443.2-445.2 K). Values of $\Delta H$ are given in Table 1. It was clear that recrystallization started in the amorphized sample.

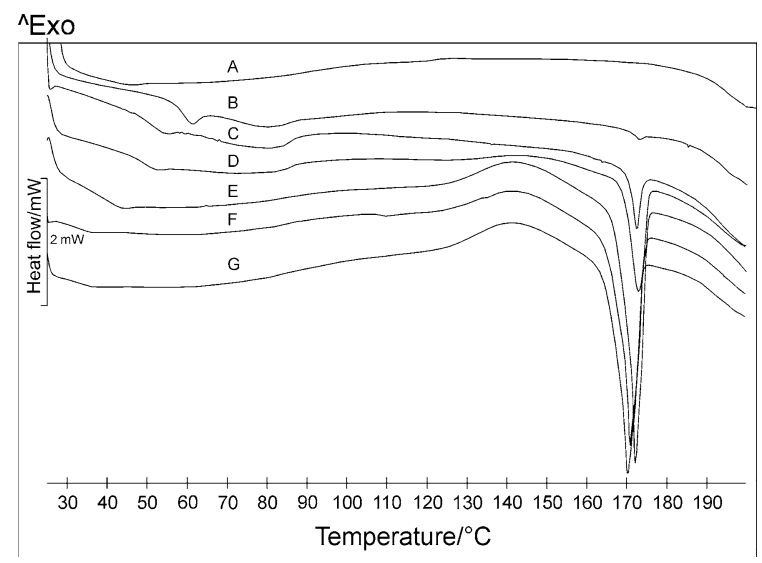

Fig. 5 Preliminary stability testing: $(A)$ fresh sample, $(B)$ sample stored for 30 days, $(C)$ sample stored for 34 days, $(D)$ sample stored for 45 days, $(E)$ sample stored for 76 days, $(F)$ sample stored for 96 days, $(G)$ : sample stored for 109 days

Table 1 Preliminary stability testing: changes in $\Delta H$ determined by DSC measurement

\begin{tabular}{lc}
\hline Duration of storage/day & $\Delta H / \mathrm{Jg}^{-1}$ \\
\hline 0 & 0.00 \\
30 & 0.55 \\
34 & 4.10 \\
45 & 15.82 \\
76 & 41.65 \\
96 & 42.64 \\
109 & 40.96 \\
\hline
\end{tabular}




\section{Conclusions}

In the course of this study, CLP was amorphized by the solvent method. Both ethanol and methanol as solvent resulted in amorphous samples. Either can be a suitable solvent for amorphization, but ethanol is preferred in view of the ICH guidelines relating to residual solvent. Methanol belongs to Class 2, and ethanol in the less dangerous Class 3. In the sample drying procedures, blown room temperature air, and vacuum drying have the same effectiveness. $T_{\mathrm{g}}$ was determined to be $88.9{ }^{\circ} \mathrm{C}(362.1 \mathrm{~K})$, the quotient $T_{\mathrm{g}} / T_{\mathrm{m}}$ was 0.80 , so CLP is a good glass former. The results of the preliminary stability testing indicated that recrystallization occurred in the pure amorphized API after 30 days at room temperature. The application of crystallization inhibitors is therefore suggested.

Open Access This article is distributed under the terms of the Creative Commons Attribution Noncommercial License which permits any noncommercial use, distribution, and reproduction in any medium, provided the original author(s) and source are credited.

\section{References}

1. Cui Y. A material science perspective of pharmaceutical solids. Int J Pharm. 2007;339:3-18.

2. Yu L. Amorphous pharmaceutical solids: preparation, characterization and stabilization. Adv Drug Deliver Rev. 2001;48:27-42.

3. Chawla G, Gupta P, Thilagavathi R, Chakraborti AK, Bansal AK. Characterization of solid-state forms of celecoxib. Eur J Pharm Sci. 2003;20:305-17.

4. Vippagunta SR, Brittain HG, Grant DJW. Crystalline solids. Adv Drug Deliver Rev. 2001;48:3-26.

5. Rodríguez-Spong B, Price CP, Jayasankar A, Matzger AJ, Rodríguez-Hornedo N. General principles of pharmaceutical solid polymorphism: a supramolecular perspective. Adv Drug Deliver Rev. 2004;56:241-74.

6. Zhang GGZ, Law D, Schmitt EA, Qiu Y. Phase transformation consideration during process development and manufacture of solid oral dosage forms. Adv Drug Deliver Rev. 2004;56:371-90.

7. Takeuchi H, Nagira S, Yamamoto H, Kawashima Y. Solid dispersion particles of amorphous indomethacin with fine porous silica particles by using spray-drying method. Int $\mathrm{J}$ Pharm. 2005;293:155-64.

8. Hancock BC, Parks M. What is the true solubility advantage for amorphous pharmaceuticals? Pharm Res. 2000;17:397-403.

9. Singhal D, Curatolo W. Drug polymorphism and dosage form design: a practical perspective. Adv Drug Deliver Rev. 2004;56: 335-47.

10. Chadha R, Kashid N, Jain DVS. Characterization and quantification of amorphous content in some selected parenteral cephalosporins by calorimetric method. J Therm Anal Calorim. 2005; 81:277-84.
11. Craig DQM, Royall PG, Kett VL, Hopton ML. The relevance of the amorphous state to pharmaceutical dosage forms: glassy drugs and freeze dried systems. Int J Pharm. 1999;179:179-207.

12. Pokharkar VB, Mandpe LP, Padamwar MN, Ambike AA, Mahadik KR, Paradkar A. Development, characterization and stabilization of amorphous form of a low $T_{\mathrm{g}}$ drug. Powder Technol. 2006;167:20-5.

13. Watanabe T, Hasegawa S, Wakiyama N, Kusai A, Senna M. Comparison between polyvinylpyrrolidone and silica nanoparticles as carriers for indomethacin in a solid state dispersion. Int J Pharm. 2003;250:283-6.

14. Kim J-H, Choi H-K. Effect of additives on the crystallization and the permeation of ketoprofen from adhesive matrix. Int J Pharm. 2002;236:81-5.

15. Takeuchi H, Nagira S, Yamamoto H, Kawashima Y. Solid dispersion particles of tolbutamide prepared with fine silica particles by the spray-drying method. Powder Technol. 2004;141:187-95.

16. Szabó-Révész P, Laczkovich O, Ambrus R, Szüts A, Aigner Z. Protocols for amorphization of crystalline solids through the application of pharmaceutical technological processes. Eur J Pharm Sci. 2007;32:26. doi:10.10166j.ejps.2007.05.036.

17. Giron D. Applications of thermal analysis and coupled techniques in pharmaceutical industry. J Therm Anal Calorim. 2002;68: 335-57.

18. Gombás Á, Szabó-Révész P, Kata M, Regdon G Jr, Erős I. Quantitative determination of $\alpha$-lactose monohydrate by DSC. J Therm Anal Calorim. 2002;68:503-10.

19. Kerč J, Srčič S. Thermal analysis of glassy pharmaceuticals. Thermochim Acta. 1995;248:81-95.

20. Hancock BC, Zografi G. Characteristics and Significance of the Amorphous State in Pharmaceutical Systems. J Pharm Sci. 1997; 86:1-12.

21. Gomez Y, Adams E, Hoogmartens J. Analysis of purity in 19 drug product tablets containing clopidogrel: 18 copies versus the original brand. J Pharmaceut Biomed. 2004;34:341-8.

22. Bousquet A, Castro B, Germain JS. Polymorphic form of clopidogrel hydrogen sulfate, US Patent 6,504,030, Jan 07 2003; ref. Chem. Abstract 132 (2000) 54841n.

23. Uvarov V, Popov I. Development and metrological characterization of quantitative X-ray diffraction phase analysis for the mixture of clopidogrel bisulphate polymorphs. J Pharmaceut Biomed. 2008;46:676-82.

24. Lohray BB, Lohray VB, Pandey B, Dave MG. Polymorph and amorphous form of (S)-(+)-clopidogrel bisulfate, WO 2004/ 081016, 23 Sept 2004.

25. Németh Z, Demeter Á, Pokol Gy. Quantifying low levels of polymorphic impurity in clopidogrel bisulphate by vibrational spectroscopy and chemometrics. J Pharmaceut Biomed. 2009;49: $32-41$.

26. Aaltonen J, Alles $\varnothing$ M, Mirza S, Koradia V, Gordon KC, Rantanen J. Solid form screening - a review. Eur J Pharm Biopharm. 2009; 71:23-37.

27. International conference on harmonization Q3C, impurities: residual solvents. 1998. http://www.emea.europa.eu/pdfs/human/ ich/028395en.pdf of subordinate document. Accessed March 1998. 